\title{
A ascensão da China na economia mundial: efeitos sobre o Brasil e América Latina
}

\author{
Jose Gabriel Porcile Meirelles \\ Wellington Pereira**
}

RESUMO - A análise das oportunidades e desafios que se abrem para o Brasil na economia internacional deve necessariamente levar em conta o novo cenário definido pela integração plena da China e da Índia ao comércio. A expansão da demanda de commodities impulsionada por esses países tem sido uma fator favorável ao crescimento econômico. Ao mesmo tempo, ela tende a reforçar uma especialização em setores que no longo prazo não são os mais dinâmicos do ponto de vista de demanda e da geração de tecnologia. Tanto os indicadores de especialização do Brasil, como a análise do conteúdo tecnológico do comércio com a China, confirmam essa preocupação com relação à natureza da inserção brasileira no ciclo recente de expansão do comércio mundial.

Palavras-chave: Comércio internacional. China. Exportações brasileiras.

\section{INTRODUÇÃO}

A ascensão da economia chinesa a um lugar de destaque no comércio é, sem dúvida, uma das mudanças mais importantes ocorridas nas últimas décadas, redefinindo as modalidades e intensidade dos fluxos de comércio e investimento em nível global. Os seus efeitos sobre América Latina e sobre o Brasil em particular têm várias facetas. Por um lado, a China é uma força impulsora do comércio e por isso tem efeitos benéficos sobre as taxas de crescimento, especialmente sobre os exportadores de commodities e de bens de capital mais complexos. Por outro lado, na medida em que no caso latino-americano a demanda chinesa concentra-se em commodities com baixo nível de processamento, ela tende a reforçar um padrão de especialização internacional que é menos dinâmico quanto à geração de tecnologia. Finalmente, no caso das economias latino-americanas cujas exportações dependem bastante de atividades intensivas em mão-de-obra (América Central e, em menor medida o México), o efeito da concorrência chinesa tem sido negativo.

Neste artigo, discutem-se rapidamente as distintas facetas do impacto da China sobre América Latina e Brasil. Na primeira seção analisa-se a composição dos fluxos de comércio.

\footnotetext{
* PhD em Economic History - London School of Economics (1995). Atualmente é Professor Associado do Departamento de Economia da Universidade Federal do Paraná. Endereço eletrônico: porcile@ufpr.br

** Mestre em Economia pela Universidade Federal do Paraná. Professor do departamento de economia (DEPECON-UFPR).Endereço Eletrônico: wellington.pereira@brde.com.br
} 
$\mathrm{Na}$ segunda seção, discutem-se os desafios que a relação com a China trazem para o Brasil do ponto de vista comercial.

\section{CHINA E ÁSIA NO COMÉRCIO MUNDIAL}

A rapidez com que a China se transformou num ator de primeira linha no comércio mundial é notável. A tabela 1 mostra as cotas das exportações de algumas regiões na economia mundial.

TABELA 1 - EVOLUÇÃO PERCENTUAL DAS COTAS DE EXPORTAÇÕES POR REGIÃO - 1985-2003

\begin{tabular}{|c|c|c|c|c|c|}
\hline Região/País & 1985 & 1990 & 1995 & 2000 & 2003 \\
\hline \multicolumn{6}{|l|}{ União Européia } \\
\hline Manufaturas baseadas em RRNN & 45.70 & 47.95 & 44.05 & 41.70 & 42.69 \\
\hline Manufaturas de alta tecnologia & 36.01 & 35.60 & 29.26 & 28.39 & 29.51 \\
\hline Manufaturas de baixa tecnologia & 48.73 & 45.54 & 36.81 & 30.85 & 31.11 \\
\hline Manufaturas de mediana tecnologia & 46.82 & 50.04 & 45.12 & 41.67 & 43.13 \\
\hline Manufaturas não baseadas em RRNN & 45.00 & 45.36 & 38.54 & 34.72 & 35.87 \\
\hline Outros & 30.62 & 39.77 & 27.66 & 29.82 & 36.36 \\
\hline Recursos Naturais & 18.21 & 20.47 & 19.90 & 16.47 & 16.94 \\
\hline Todos os sectores & 38.48 & 41.66 & 36.59 & 33.27 & 34.42 \\
\hline \multicolumn{6}{|l|}{ China } \\
\hline Manufaturas baseadas em RRNN & 1.11 & 1.28 & 2.13 & 2.84 & 3.55 \\
\hline Manufaturas de alta tecnologia & 0.36 & 1.35 & 3.63 & 6.42 & 9.94 \\
\hline Manufaturas de baixa tecnologia & 4.50 & 9.10 & 15.56 & 19.39 & 22.09 \\
\hline Manufaturas de mediana tecnologia & 0.43 & 1.38 & 2.62 & 3.79 & 5.03 \\
\hline Manufaturas não baseadas em RRNN & 1.48 & 3.41 & 6.13 & 8.26 & 10.58 \\
\hline Outros & 0.72 & 0.67 & 1.39 & 1.90 & 2.58 \\
\hline Recursos Naturais & 2.43 & 2.57 & 2.51 & 2.25 & 2.26 \\
\hline Todos os sectores & 1.61 & 2.80 & 4.82 & 6.41 & 8.12 \\
\hline \multicolumn{6}{|l|}{ Estados Unidos } \\
\hline Manufaturas baseadas em RRNN & 8.47 & 10.19 & 10.59 & 10.16 & 9.13 \\
\hline Manufaturas de alta tecnologia & 24.17 & 21.37 & 19.82 & 18.33 & 14.34 \\
\hline Manufaturas de baixa tecnologia & 5.22 & 5.91 & 7.93 & 9.18 & 7.26 \\
\hline Manufaturas de mediana tecnologia & 13.91 & 12.37 & 13.70 & 15.18 & 13.07 \\
\hline Manufaturas não baseadas em RRNN & 13.84 & 12.85 & 14.00 & 14.86 & 12.15 \\
\hline Outros & 16.05 & 14.42 & 12.94 & 10.27 & 11.73 \\
\hline Recursos Naturais & 8.12 & 8.88 & 9.54 & 7.16 & 6.60 \\
\hline Todos os sectores & 11.53 & 11.79 & 12.80 & 12.97 & 10.94 \\
\hline \multicolumn{6}{|l|}{ América Latina } \\
\hline Manufaturas baseadas em RRNN & 6.95 & 5.90 & 6.22 & 6.65 & 6.72 \\
\hline Manufaturas de alta tecnologia & 2.14 & 1.75 & 2.19 & 3.80 & 3.70 \\
\hline Manufaturas de baixa tecnologia & 3.21 & 3.28 & 4.16 & 5.44 & 5.24 \\
\hline Manufaturas de mediana tecnologia & 2.48 & 2.85 & 3.86 & 5.14 & 5.00 \\
\hline Manufaturas não baseadas em RRNN & 2.60 & 2.70 & 3.46 & 4.76 & 4.63 \\
\hline Outros & 4.28 & 3.18 & 3.72 & 4.95 & 5.13 \\
\hline Recursos Naturais & 12.44 & 11.46 & 12.58 & 12.97 & 13.18 \\
\hline Todos os sectores & 5.78 & 4.69 & 5.15 & 6.11 & 6.10 \\
\hline
\end{tabular}

FONTE: CEPAL, Divisão de Desenvolvimento Produtivo e Empresarial.

A China multiplicou por oito sua participação nas exportações no total dos setores (embora partindo de um patamar muito baixo) e entre 1985 e 2003, e alcançou valores 
superiores a $20 \%$ no caso dos setores de baixa tecnologia. No mesmo período, a União Européia reduziu sua participação, enquanto que América Latina e os Estados Unidos as mantiveram estável. Naturalmente, esses dados também refletem as distintas dimensões (em PIB e população) dos países considerados. Para ter uma idéia do padrão de especialização, é necessário um indicador que evite essa distorção. Na Tabela 2, apresentam-se os coeficientes de especialização dos distintos países, definidos como a relação entre a participação de um país nas exportações mundiais num certo setor e as exportações desse país no total das exportações mundiais. Setores nos quais o coeficiente de especialização é maior do que 1 são setores nos quais o país mostra vantagens comparativas no comércio internacional.

TABELA 2 - COEFICIENTE DE ESPECIALIZAÇÃO

\begin{tabular}{|c|c|c|c|c|c|}
\hline Região/País & 1985 & 1990 & 1995 & 2000 & 2003 \\
\hline \multicolumn{6}{|l|}{ União Européia } \\
\hline Manufaturas baseadas em RRNN & 1.188 & 1.151 & 1.204 & 1.253 & 1.240 \\
\hline Manufaturas de alta tecnologia & 0.936 & 0.855 & 0.800 & 0.853 & 0.857 \\
\hline Manufaturas de baixa tecnologia & 1.266 & 1.093 & 1.006 & 0.927 & 0.904 \\
\hline Manufaturas de mediana tecnologia & 1.217 & 1.201 & 1.233 & 1.252 & 1.253 \\
\hline Manufaturas não baseadas em RRNN & 1.169 & 1.089 & 1.053 & 1.044 & 1.042 \\
\hline Outros & 0.796 & 0.955 & 0.756 & 0.896 & 1.057 \\
\hline Recursos Naturais & 0.473 & 0.491 & 0.544 & 0.495 & 0.492 \\
\hline Todos os sectores & 1.000 & 1.000 & 1.000 & 1.000 & 1.000 \\
\hline \multicolumn{6}{|l|}{ China } \\
\hline Manufaturas baseadas em RRNN & 0.692 & 0.457 & 0.443 & 0.443 & 0.437 \\
\hline Manufaturas de alta tecnologia & 0.222 & 0.482 & 0.753 & 1.001 & 1.224 \\
\hline Manufaturas de baixa tecnologia & 2.803 & 3.246 & 3.228 & 3.026 & 2.721 \\
\hline Manufaturas de mediana tecnologia & 0.269 & 0.493 & 0.543 & 0.592 & 0.620 \\
\hline Manufaturas não baseadas em RRNN & 0.922 & 1.215 & 1.272 & 1.289 & 1.303 \\
\hline Outros & 0.450 & 0.240 & 0.289 & 0.297 & 0.318 \\
\hline Recursos Naturais & 1.512 & 0.918 & 0.521 & 0.352 & 0.278 \\
\hline Todos os sectores & 1.000 & 1.000 & 1.000 & 1.000 & 1.000 \\
\hline \multicolumn{6}{|l|}{$\begin{array}{l}\text { Estados Unidos } \\
\end{array}$} \\
\hline Manufaturas baseadas em RRNN & 0.734 & 0.864 & 0.827 & 0.784 & 0.834 \\
\hline Manufaturas de alta tecnologia & 2.096 & 1.813 & 1.549 & 1.413 & 1.311 \\
\hline Manufaturas de baixa tecnologia & 0.453 & 0.501 & 0.619 & 0.708 & 0.664 \\
\hline Manufaturas de mediana tecnologia & 1.206 & 1.049 & 1.070 & 1.171 & 1.194 \\
\hline Manufaturas não baseadas em RRNN & 1.200 & 1.090 & 1.094 & 1.146 & 1.111 \\
\hline Outros & 1.392 & 1.222 & 1.011 & 0.792 & 1.072 \\
\hline Recursos Naturais & 0.704 & 0.753 & 0.745 & 0.552 & 0.603 \\
\hline Todos os sectores & 1.000 & 1.000 & 1.000 & 1.000 & 1.000 \\
\hline \multicolumn{6}{|l|}{ América Latina } \\
\hline Manufaturas baseadas em RRNN & 1.203 & 1.259 & 1.208 & 1.088 & 1.103 \\
\hline Manufaturas de alta tecnologia & 0.370 & 0.374 & 0.426 & 0.622 & 0.608 \\
\hline Manufaturas de baixa tecnologia & 0.556 & 0.701 & 0.808 & 0.889 & 0.860 \\
\hline Manufaturas de mediana tecnologia & 0.429 & 0.607 & 0.749 & 0.840 & 0.820 \\
\hline Manufaturas não baseadas em RRNN & 0.450 & 0.575 & 0.672 & 0.778 & 0.759 \\
\hline Outros & 0.740 & 0.678 & 0.723 & 0.810 & 0.842 \\
\hline Recursos Naturais & 2.153 & 2.445 & 2.444 & 2.122 & 2.162 \\
\hline Todos os sectores & 1.000 & 1.000 & 1.000 & 1.000 & 1.000 \\
\hline
\end{tabular}

FONTE: CEPAL, Divisão de Desenvolvimento Produtivo e Empresarial. 
Sem dúvida, destaca-se a especialização da China nos setores de baixa tecnologia. Mas não é menos destacável o aumento logrado nos setores de alta tecnologia (de aproximadamente 0.2 para 1.2). Esse comportamento é muito sugestivo da existência de um processo de upgrading na composição das exportações chinesas. No caso da América Latina, é clara a especialização em recursos naturais e em menor medida em manufaturas intensivas em recursos naturais. Mas vale a pena notar o aumento do coeficiente nas manufaturas de média e alta tecnologia, indicando uma tendência positiva.

TABELA 3 - COMPOSIÇÃO DAS EXPORTAÇÕES (\%) POR INTENSIDADE TECNOLÓGICA - 2004

\begin{tabular}{l|rr|r|r|rr|}
\hline & Argentina & Brasil & Chile & México & China & India \\
\hline Recursos Naturais & 51.4 & 32.6 & 41.5 & 14.6 & 3.2 & 15.6 \\
Manufaturas baseadas em RRNN & 24.5 & 21.9 & 49.2 & 6.4 & 6.9 & 29.8 \\
Manufaturas de baixa tecnologia & 7.4 & 11.0 & 2.1 & 13.5 & 39.2 & 35.5 \\
Manufaturas de média tecnologia & 14.1 & 24.9 & 5.5 & 37.5 & 19.0 & 12.8 \\
Manufaturas de alta tecnologia & 1.7 & 7.9 & 0.5 & 24.2 & 30.5 & 5.4 \\
Outros & 0.9 & 1.7 & 1.2 & 3.8 & 1.1 & 0.9 \\
Total & 100 & 100 & 100 & 100 & 100 & 100 \\
\hline
\end{tabular}

FONTE: CEPAL, Divisão de Desenvolvimento Produtivo e Empresarial.

A Tabela 3 mostra as diferenças na composição do comércio no caso da América Latina, e as compara com China e Índia. É claro o domínio chinês nos setores de baixa e alta tecnologia. Brasil e México se destacam na comparação regional nos setores de média tecnologia, superando inclusive à China nesse setor. México tem uma presença importante no setor de alta tecnologia, em grande medida pelas exportações das atividades maquiladoras (intensivas em mão-de-obra) no setor eletro-eletrônico.

\section{DESAFIOS PARA O BRASIL}

a) Como a China afeta a inserção do Brasil?

Os desafios para o comércio do Brasil frente ao novo papel das economias asiáticas em geral e da China, em particular, podem-se resumir do seguinte forma: como aproveitar as oportunidades que surgem da expansão do comércio mundial para estimular não apenas um aumento das quantidades exportadas, mas também a diversificação das exportações na direção de setores intensivos em tecnologia? A literatura sugere que esta não é uma tarefa fácil.

Num trabalho recente, Jenkins et al (2008) mostra que a expansão da China reforça o padrão dominante de especialização em recursos naturais da América Latina. Os custos dos bons tempos (atuais) no comércio poderiam reforçar um tipo de inserção que é notadamente pouco favorável (focada nos recursos naturais) quando a economia mundial cresce menos. A 
tendência positiva dos termos de troca que se observa em anos recentes não é tão significativa quando se observam as tendências seculares (OCAMPO; PARRA, 2005).

Essa idéia é reforçada pelos resultados da análise de Eichengreen e Tong (2006). Esses autores mostram que a China gera dois tipos de estímulos positivos: na direção das commodities com muito pouco valor adicionado e na direção de bens de capital mais complexos requeridos pelo avanço da industrialização. O primeiro tipo de demanda tem beneficiado os países latino-americanos, enquanto que o segundo beneficia países de industrialização avançada, como Estados Unidos, Coréia e Japão.

No caso do Brasil, 2/3 das exportações destinadas à China se referem à soja, minérios de ferro e aço. $\mathrm{O}$ impulso recebido pelas exportações de commodities tem ajudado a valorizar o real a reduzir a competitividade de alguns setores manufatureiros. Esses fatores sugerem a necessidade de formular uma política exportadora com foco na diversificação da pauta do comércio com Ásia.

\section{b) As relações comerciais entre Brasil e China}

As relações comerciais entre Brasil e China sempre ocorreram, mas foi no período recente que houve um crescimento muito forte e acelerado. A China é um país que estabeleceu um plano de crescimento e desenvolvimento de longo prazo. Ela possui uma das maiores populações do mundo, a qual cada vez mais passa a ter acesso a recursos que geram impactos sobre a demanda. Esses impactos têm sido as exportações brasileiras.

O Brasil como um país rico em diversas commodities tornou-se parceiro estratégico para a China. Ocorre que somos um dos grandes fornecedores mundiais de dois produtos importantes que continuarão ajudando no crescimento da China nos próximos anos: soja e minérios de ferro. Por um lado, tem-se a fome da população que precisa ser saciada como alimentos os quais a China não consegue suprir sozinha. Por outro lado, tem-se a fome da indústria por aço. Não é a toa que a China começa a ver o Brasil como um parceiro essencial para a manutenção e ampliação de seu crescimento.

Diversas empresas chinesas já atuam no Brasil em segmentos estratégicos para economia da China. Setores como energia (biocombustíveis e álcool), transportes e logística e usinas de aço são alguns dos exemplos que podem ser citados e que contemplam interesses chineses. Já no outro lado do mundo, algumas das grandes empresas brasileiras seguiram a onda da internacionalização já adotada por diversas companhias dos EUA, Europa e Japão. A Embraer, por exemplo, já possui uma unidade na China. A estratégia se resume, em grande parte, a associações com empresas chinesas, pois o mercado chinês é muito bem regulado 
pelos interesses do partido comunista. Uma empresa como a Embraer que se torna cada vez mais global precisa estar presente em um dos maiores mercados do mundo (e que tende a crescer vertiginosamente), pois além de atender com o fornecimento de aeronaves, precisa prestar serviços de assistência a seus clientes.

A WEG, uma empresa catarinense que decidiu colocar suas bases na China é outro caso de sucesso com a internacionalização. Hoje, esse tipo de atitude é quase uma regra para as grandes empresas que buscam a internacionalização e a manutenção de altos níveis de competitividade no exterior. O crescimento da renda per-capita chinesa favorecerá cada vez mais a entrada de empresas neste mercado que, mesmo sob as amarras impostas pelo governo chinês, vem se destacando como um dos maiores do mundo. As "benesses" desenvolvidas no Ocidente cada vez mais cativam o desejo dos consumidores chineses.

Como foi afirmado, o Brasil desempenha papel fundamental e deve utilizar (intensamente) desse ativo relacional com a China, a seu favor. $\mathrm{Na}$ seqüência, são apresentadas algumas estatísticas que resumem as relações comerciais entre China e Brasil no período de 1990 a 2005.

A tabela abaixo mostra as exportações e importações do Brasil destinadas/originadas da China. Além disso, trata-se de uma tabela que discrimina os fluxos comerciais mediante o conteúdo tecnológico das mercadorias ${ }^{5}$. A importância em se observar as transações comerciais sob a perspectiva tecnológica já foi amplamente debatida e outorgada por diversos autores. Sobretudo no que se refere aos países em desenvolvimento, é de suma importância examinar as transações comerciais a partir do conteúdo tecnológico incorporado a bens transacionados. É com esta tentativa que se consegue observar o tipo de relação que é estabelecida entre dois países, regiões ou blocos.

\footnotetext{
${ }^{5}$ Utiliza a metodologia desenvolvida por Lall (2000). O autor classifica as categorias de produtos em grupos tecnológicos a partir da Standard International Trade Classification (SITC) em três dígitos (Rev. 3). São 10 categorias de produtos mediante sua respectiva classificação tecnológica. Estes são reagrupados em quatro grandes grupos: Produtos Baseados em Recursos, Baixa Tecnologia, Média Tecnologia e Alta Tecnologia.
} 
TABELA 4 - FLUXOS COMERCIAIS BRASILEIROS COM A CHINA (US\$ milhões) 1990, 1995, 2000 e 2005

\begin{tabular}{|c|c|c|c|c|c|c|c|c|}
\hline \multirow{2}{*}{ Descrição } & \multicolumn{2}{|c|}{1990} & \multicolumn{2}{|c|}{1995} & \multicolumn{2}{|c|}{2000} & \multicolumn{2}{|c|}{2005} \\
\hline & $\operatorname{Exp}$ & $\mathrm{Imp}$ & Exp & $\mathrm{Imp}$ & Exp & Imp & Exp & Imp \\
\hline Produtos primários & 29,8 & 94,6 & 37,14 & 38,14 & 476.44 & 45,12 & $2.962,1$ & 98,1 \\
\hline Baseados em recursos (BR 1) & 128,5 & 0.2 & 707.57 & 22,48 & 130.42 & 12.99 & 730,9 & 83,0 \\
\hline Qutros basead $\alpha$ em recurs $\alpha$ (BR 2) & 52,7 & 169 & 185,08 & 144,14 & 299,96 & 22593 & 2.046 .7 & 613.9 \\
\hline Têxteis, vestuário e calçados (BT 1) & 0.1 & 0,3 & 0,83 & 222,10 & 0,56 & 91,45 & 9.9 & 354,8 \\
\hline Qutros produtos de baixa tecnologia (BT 2) & 70,9 & 19 & 105,83 & 201,91 & 26.61 & 145,58 & 413,0 & 366,3 \\
\hline Automobilistica (MT 1) & 6,5 & 0.1 & 68,90 & 30,50 & 10,81 & 10,25 & 50,3 & 87,3 \\
\hline Processos (MT 2) & 91.4 & 0.4 & 22.75 & 73,27 & 51,08 & 33,60 & 261.1 & 324,9 \\
\hline Engenharia (MiT 3) & 0.7 & 45 & 50,70 & 153.47 & 33,89 & 157,47 & 265,5 & 805,5 \\
\hline Eletrônica e elétricos (AT 1) & 0,4 & 0,4 & 24,23 & 123,87 & 14,58 & 419,65 & 69.9 & $2.200,3$ \\
\hline Qutros produtos de alta tecnologia (AT 2) & 0,7 & 05 & 0.71 & 30,41 & 40,87 & 80,09 & 24,3 & 397,4 \\
\hline Tot $\bar{a}$ & 31,8 & 1198 & $1.203,8$ & $1.040,3$ & $1.085,2$ & $1.222,1$ & $6.833,7$ & $5.331,6$ \\
\hline
\end{tabular}

FONTE: SECEX - elaboração própria.

Verifica-se que, com exceção do ano 2000, o Brasil vem mantendo superávit com o país asiático. Apesar disso, trata-se de um resultado apertado e que quando verificado a partir da perspectiva tecnológica mostra que somos amplamente dependentes do fornecimento de produtos de alta tecnologia. Por outro lado, as exportações de produtos primários e daqueles baseados em recursos estão em trajetória ascendente.

O tipo de classificação tecnológica apontada na tabela permite ver que além da dependência brasileira em produtos que incorporam maior tecnologia, corroboram-se os resultados devastadores que os setores intensivos em mão-de-obra, tal como têxteis, vestuários e calçados enfrentam diante dos concorrentes chineses. É surpreendente a evolução positiva que ocorre também nessas categorias, que são bastante sensíveis ao câmbio. Basta ver que em 1995 e 2005, anos em que houve apreciação cambial, as compras desses produtos responderam mais fortemente.

Outro indicador relevante destacado faz referência ao valor médio das transações comerciais. $\mathrm{O}$ valor médio é o quociente entre o valor da transação em dólares pelo seu peso em quilogramas. Ele é utilizado como um indicativo do preço médio, de modo que os produtos com maiores valores médios tendem a ser aqueles que incorporam maior valor agregado e tecnológico. Obviamente, há exceções e discrepâncias para este indicador. Um exemplo se refere às pedras preciosas que possuem peso baixo, mas valor elevado o que gera um valor médio que poderia indicar elevada incorporação tecnológica - o que não se aplica. Mas, apesar de problemas como o apontado, o indicador é bastante útil para efetuar análises no âmbito das relações tecnológicas, como proxy para a densidade industrial e tecnológica dos bens comercializados

O primeiro sinal que se observa na tabela é a evolução do valor médio total das importações frente às exportações. Verifica-se que com o passar dos anos o valor das 
compras cresce muito mais rápida e intensamente que aquele ocorrido para as vendas. Este é o primeiro sinal do tipo de relação que se estabelece entre Brasil e China: a dependência de produtos eletrônicos, sobretudo, é uma das respostas para esse movimento. Assim, fica claro que mais uma vez a relação comercial do Brasil com um grande mercado tal como o chinês tende a reforçar uma relação de dependência externa de produtos intensivos em tecnologia.

TABELA 5 - VALORES MÉDIOS DAS EXPORTAÇÕES E IMPORTAÇÕES DO COMÉRCIO DO BRASIL COM A CHINA (US\$) - 1990-2005

\begin{tabular}{|c|c|c|c|c|c|c|c|c|}
\hline \multirow{2}{*}{ Descrição } & \multicolumn{2}{|c|}{1990} & \multicolumn{2}{|c|}{1995} & \multicolumn{2}{|c|}{2000} & \multicolumn{2}{|c|}{2005} \\
\hline & Exp & $\operatorname{Imp}$ & Exp & $\operatorname{Imp}$ & Exp & Imp & Exp & Imp \\
\hline Bo hutos primáxi os & 1,40 & 0,10 & 0,53 & 0,67 & 0,22 & 0,06 & 0,30 & 0,20 \\
\hline Eaxados em recus os (ERI) & 0,60 & 1,60 & 0,46 & 1,96 & 0,48 & 1,06 & 0,50 & 1,70 \\
\hline Outos baxados em recus os (ER2) & $0, \infty$ & 0,10 & $0, \infty$ & 0,22 & 0,02 & 0,22 & 0,00 & 0,50 \\
\hline T'êxteis, vestuário e alģados (BT' I) & 6,40 & 980 & 4,11 & 8,13 & 3,98 & 4,41 & 5,90 & 3,50 \\
\hline Outos de baika terologia (ET2) & 0,40 & 240 & 0,43 & 3,06 & 0,42 & 1,63 & 0,60 & 1,60 \\
\hline Automilnírtica (PrT 1) & 8,80 & 260 & 4,66 & 3,56 & 12,28 & $1, \infty$ & 5,50 & 2,30 \\
\hline B ocessos (MTS) & 0,20 & 1,00 & 0,77 & 2,55 & 0,65 & 1,67 & 0,60 & 270 \\
\hline Exgerharix (prtis) & 12,50 & 11,90 & $13, \infty$ & 7,36 & 4,88 & 4,06 & 680 & 5,00 \\
\hline Eettônica e elétric os (A'T1) & 12,60 & 8,60 & 10,70 & 12,37 & 808 & 7,78 & 10,40 & 13,40 \\
\hline Qutos produtos de alta tecrologin (AT2) & 197,40 & 12,50 & 7,25 & 12,10 & 181,14 & 17,19 & 168,00 & 29,90 \\
\hline Total & 0,10 & 0,10 & 0,14 & 1,16 & 0,06 & 0,62 & 0,10 & 200 \\
\hline
\end{tabular}

FONTE: SECEX - elaboração própria.

No entanto, verifica-se que a categoria outros produtos de alta tecnologia (AT2) mostra valores médios para as exportações muito superiores àqueles vistos para as importações. Isso é reflexo da atuação de empresas como a Embraer, porque aeronaves e componentes do segmento estão incorporados naquele grupo de produtos. Outro destaque interessante refere-se à área automobilística, pois seus VMs das exportações oscilam muito perante os verificados para as importações. A redução do VM dos produtos do grupo de têxteis, vestuários e calçados mostra que temos adquirido itens que possuem valor médio decrescente mostrando uma vez mais que a especialização chinesa (e asiática, em geral) também no fornecimento de produtos intensivos em trabalho e sem incorporação tecnológica.

Outro exercício realizado foi verificar a posição dos países parceiros-comerciais do Brasil nas exportações e importações dos anos 1990, 1995, 2000 e 2005. O foco mais uma vez foi a China de modo a visualizar a evolução do peso relativo daquele país no âmbito global do comércio brasileiro. Surpreendentemente, ao longo do tempo a China passa a ser um dos principais fornecedores para o Brasil e, ao mesmo tempo, comprador de produtos brasileiros. 
TABELA 6 - POSICIONAMENTO DA CHINA NAS RELAÇÕES COMERCIAIS BRASILEIRAS -1990

\begin{tabular}{c|c|c}
\hline \multirow{2}{*}{} & Exportações & Importações \\
\cline { 2 - 3 } & Ranking & Raking \\
\hline 1990 & 17 & 27 \\
1995 & 11 & 11 \\
2000 & 12 & 11 \\
2005 & 3 & 4 \\
\hline
\end{tabular}

FONTE: SECEX - elaboração própria.

Em 1990, a China respondia pela $17^{a}$ posição pelo lado das vendas e $27^{a}$ pelo lado das compras. Em 15 anos ocorre uma forte reversão deste quadro, de modo que a China passa a ser o terceiro "cliente" das vendas brasileiras - sobretudo, commodities, e o quarto maior fornecedor de produtos para o Brasil. Esse último resultado pode ser visto pelo aumento das importações de produtos eletrônicos.

A China não só passou a representar um papel de destaque pelo lado das compras e vendas brasileiras, como também contribuiu para diversificar as importações brasileiras. A tabela abaixo mostra a participação dos 10 principais produtos transacionados com a China e também apresenta a quantidade total de itens comercializados ao longo de cada ano selecionado.

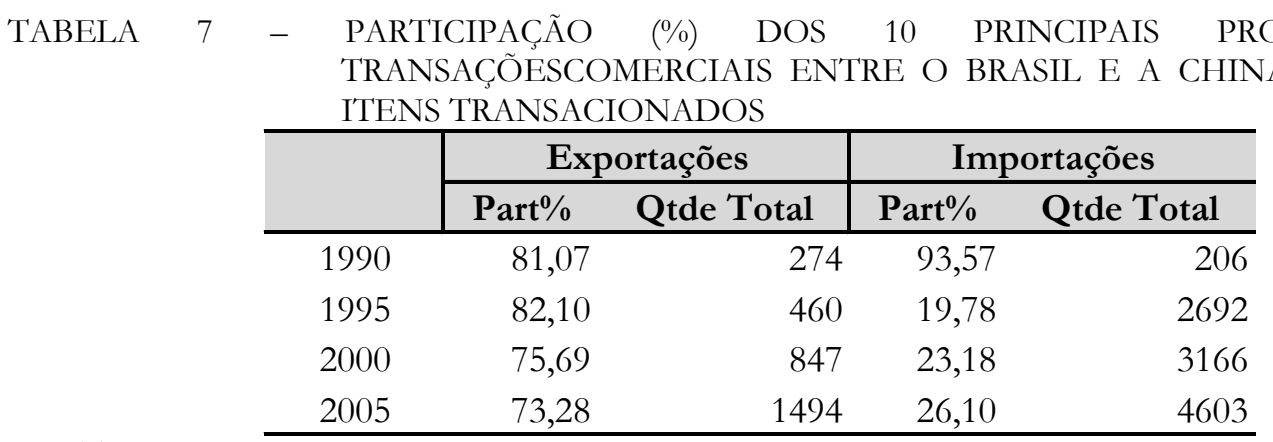

FONTE: SECEX- elaboração própria.

Verifica-se pela tabela acima que nas exportações não ocorre uma forte desconcentração das vendas com o passar dos anos. Apesar do aumento na quantidade total de produtos exportados (de 274 em 1990 para 1.494 em 2005), a concentração se manteve em apenas 10 itens.

O mesmo já não pode ser dito para as importações. Além da rápida queda da participação relativa, o aumento da quantidade total de produtos importados cresceu quatro vezes mais do que se verificou para as exportações. Assim, a dependência pelo lado das importações foi se diversificando ao longo do tempo, apesar de este efeito ter sido minorado devido ao maior aumento do leque de produtos adquiridos. 
Em suma, verifica-se que a China tem sido muito mais dinâmica não somente pelo fato de que avança na produção e exportação de produtos de maior valor agregado/tecnológico, como também diversifica muito mais sua oferta do que a sua demanda, que está concentrada em poucos produtos.

Fica o registro para um aprimoramento deste ponto para o melhor entendimento das relações comerciais que vem sendo alinhavadas entre Brasil e China. Enquanto o país asiático vem construindo sua trajetória de crescimento e desenvolvimento econômico de longo prazo, o Brasil parece ficar estancado no tempo, concentrando sua competitividade nos produtos “de sempre”. Muda o parceiro, mas não muda o final da história.

\section{CONCLUSÕES}

A análise das oportunidades e desafios que se abrem para o Brasil na economia internacional deve necessariamente levar em conta o novo cenário definido pela integração plena da China e da Índia ao comércio. A expansão da demanda de commodities impulsionada por esses países tem se apresentado como um fator favorável ao crescimento econômico. Ao mesmo tempo, ela tende a reforçar uma especialização em setores que no longo prazo não são os mais dinâmicos do ponto de vista de demanda e da geração de tecnologia. Tanto os indicadores de especialização do Brasil, como a análise do conteúdo tecnológico do comércio com a China, confirmam essa preocupação com relação à natureza da inserção brasileira no ciclo recente de expansão do comércio mundial.

\section{REFERÊNCIAS}

EICHENGREEN, B. TONG, H. How China Is Reorganizing The World Economy, Asian Economic Policy Review, 2006, VOL. 1, ISSUE 1, PAGES 73-97.

JENKINS, R., PETERS, D. e MOREIRA, M. The impact of China on Latin America and the Caribbean, World Development, Volume 36, Issue 2, February 2008, Pages 235-253. LALL, S. The technological structure and performance of developing country manufactured exports, 1985-1998. Queen Elizabeth House - QEH Working Paper No 44, June 2000.

OCAMPO, J.A e PARRA, M.A. The terms of trade for commodities in the XXth Century, CEPAL Review, Abril 2003. 